\title{
ANALISIS PERBAIKAN KUALITAS GENTENG BETON DENGAN MENGGUNAKAN METODE TAGUCHI
}

(Control Of Process and Product Quality Used Taguchi Method)

\author{
LINANDA KAILEY ${ }^{1}$, HENRY J WATTIMANELA ${ }^{2}$ \\ ${ }^{1}$ Alumni Jurusan Matematika, FMIPA,UNPATTI \\ ${ }^{2}$ Staf Jurusan Matematika, FMIPA,UNPATTI
}

\begin{abstract}
A concrete roof tile company wanted to improve the quality and reduce product defects or rework of products, but companies in the production of concrete roof tile products still fragile because of strong press tiles that are not in accordance with predetermined specifications.

To overcome these problems, have made a study to identify factors that influence control of a strong press and concrete roof tiles to get the best settings in producing a product that is expected to perform design of experiments using Taguchi Method to factors that can be controlled by the Cement ( A), water (B), Fly Ash (C) and Dust Stone (D).

Each factor had 3 levels of treatment and based on the total number of free degrees in this experiment the orthogonal matrix $L_{27}\left(3^{13}\right)$ is used. Based on the results obtained so semenyang largest contribution to the average strength of concrete roof tile press, which is $18.642 \%$ of dust and rock that is a combination of $8.167 \%$ and the right to obtain a strong tap-concrete roof tiles desired $A_{3} A_{3} B_{1} D_{2}$.
\end{abstract}

Keywords: experiment, Orthogonal matrix, Taguchi Method, Concrete Tile

\section{PENDAHULUAN}

Industri bahan bangunan saat ini sedang mengalami persaingan yang cukup ketat, sehingga mengharuskan produsen mampu menjaga dan meningkatkan kualitas produk yang dihasilkan. Kualitas suatu produk merupakan salah satu faktor utama konsumen dalam memilih dan menentukan produk yang akan digunakan.

Sebuah perusahaan genteng beton ingin meningkatkan kualitas serta mengurangi adanya cacat produk atau pengerjaan ulang dari produk yang dihasilkan. Untuk mengatasi permasalahan tersebut, perlu diadakan suatu penelitian untuk mengidentifikasi faktor-faktor kontrol yang berpengaruh terhadap kuat tekan genteng beton dan untuk mendapatkan setting terbaik dalam menghasilkan produk yang diharapkan yaitu dengan melakukan desain eksperimen. Desain eksperimen yang baik ialah apabila eksperimen yang dilakukan sesuai dengan masalahnya dan mempunyai efisiensi yang tinggi, yaitu apabila eksperimen dilakukan dengan menggunakan biaya, waktu dan usaha yang minimum tetapi dapat memberikan informasi yang optimum (1), hal tersebut yang menjadi salah satu keunggulan dari Metode Taguchi.

Dengan melakukan desain eksperimen Taguchi, diharapkan dapat mengetahui faktor-faktor yang berpengaruh terhadap kuat tekan genteng beton dan menghasilkan kombinasi dan komposisi bahan baku yang tepat yang memberikan kuat tekan genteng beton yang diinginkan oleh konsumen serta memberikan peningkatan kualitas terhadap produk yang dihasilkan sehingga pada akhirnya dapat meningkatkan keuntungan.

Dalam Metode Taguchi digunakan matriks yang disebut matriks ortogonal untuk menentukan jumlah eksperimen minimal yang dapat memberikan informasi sebanyak mungkin tentang semua faktor yang mempengaruhi parameter. Bagian terpenting dari matriks ortogonal terletak pada pemilihan kombinasi level perlakuan (2). Matriks ortogonal diciptakan oleh Jaques Hardmand pada tahun 1897 (3).

\section{TUJUAN}

Eksperimen ini dilakukan dengan tujuan untuk mengidentifikasi faktor-faktor yang berpengaruh terhadap kuat tekan genteng beton serta menentukan kombinasi dan komposisi bahan baku genteng beton untuk menghasilkan kuat tekan genteng beton yang optimum.

\section{Bahan}

\section{BAHAN dan METODE}

Bahan yang digunakan adalah Semen, Air, Fly Ash dan Debu Batu. Sumber data dalam penentuan level dari faktor ini didapat dari data pabrik yang merupakan hasil kombinasi dari buku panduan (Soejanto, 2009). Data hasil penetapan level ini dapat dilihat pada Tabel 1.

Tabel 1. Penentuan jumlah level dan nilai level faktor

\begin{tabular}{|c|c|c|c|c|}
\hline Kode & Faktor Kontrol & Level 1 & Level 2 & Level 3 \\
\hline$A$ & Semen & $0,6 \mathrm{~kg}$ & $0,7 \mathrm{~kg}$ & $0,8 \mathrm{~kg}$ \\
\hline$B$ & Air & $0,3 \mathrm{lt}$ & $0,4 \mathrm{lt}$ & $0,5 \mathrm{lt}$ \\
\hline$C$ & Fly Ash & $0,2 \mathrm{~kg}$ & $0,3 \mathrm{~kg}$ & $0,4 \mathrm{~kg}$ \\
\hline$D$ & Debu Batu & $2,6 \mathrm{~kg}$ & $2,8 \mathrm{~kg}$ & $3,0 \mathrm{~kg}$ \\
\hline
\end{tabular}




\section{Metode}

Metode yang digunakan untuk mengumpulkan data adalah dengan cara menggunakan matriks ortogonal yang dipilih berdasarkan jumlah perhitungan derajat babas kemudian melakukan percobaan sesuai dengan matriks ortogonal yang dipilih. selanjutnya menentukan grafik linier yang sesuai, berguna untuk penempatan kolom untuk faktor dan interaksi ke dalam matriks orthogonal.

\section{Perhitungan Derajat Bebas}

Perhitungan derajat kebebasan dilakukan untuk menghitung jumlah minimum eksperimen yang harus dilakukan untuk menyelidiki faktor yang diamati.

Tabel 2. Perhitungan Derajat Bebas Total

\begin{tabular}{|c|c|c|}
\hline Faktor & Derajat bebas & Total \\
\hline$A$ & $(3-1)$ & 2 \\
\hline$B$ & $(3-1)$ & 2 \\
\hline$C$ & $(3-1)$ & 2 \\
\hline$D$ & $(3-1)$ & 2 \\
\hline$A \times B$ & $(3-1) \times(3-1)$ & 4 \\
\hline$A \times C$ & $(3-1) \times(3-1)$ & 4 \\
\hline \multicolumn{2}{|c|}{ Derajat Bebas Total } & 16 \\
\hline
\end{tabular}

\section{Pemilihan Matriks Ortogonal}

Dari perhitungan derajat bebas pada ekperimen ini, diperoleh $v_{f l}=16$ derajat bebas, dan masing-masing faktor mempunyai 3 level. Maka matriks ortogonal yang dipilih adalah yang mempunyai jumlah derajat bebas lebih besar atau sama dengan jumlah derajat bebas total dalam eksperimen ini (16 derajat bebas). Derajat bebas untuk matriks ortogonal yang paling sesuai:

$$
\begin{aligned}
& L_{9}\left(3^{4}\right)=4 \times(3-1)=8 \text { derajat bebas. } \\
& L_{27}\left(3^{13}\right)=13 \times(3-1)=26 \text { derajat bebas. }
\end{aligned}
$$

Karena derajat bebas total pada eksperimen ini adalah 16 derajat bebas, oleh karena itu matriks ortogonal $L_{27}\left(3^{13}\right)$ yang mempunyai 26 derajat bebas telah mencukupi.

Sesuai matriks ortogonal $L_{27}\left(3^{13}\right)$ yang dipilh maka grafik linier standart $L_{27}\left(3^{13}\right)$ yang diperlukan.
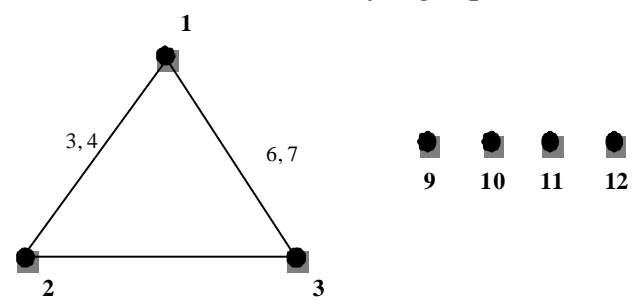

Gambar 1. Grafik linier Standart $L_{27}\left(3^{13}\right)$

Berdasarkan Gambar 1, dapat diketahui bahwa faktor $A$ ditempatkan pada kolom 1 , faktor $B$ pada kolom 2, faktor $C$ pada kolom 5 , faktor $D$ pada kolom 9 , faktor $A$ x $B$ kolom 3 dan 4, faktor $A$ x $C$ pada kolom 6 dan 7. Sedangkan untuk kolom kosong $8,10,11,12$, dan 13 ditulis " $e$ " menyatakan error. Dengan menggunakan matriks ortogonal $L_{27}\left(3^{13}\right)$ diperoleh data seperti pada Tabel 3.

\begin{tabular}{|c|c|c|c|c|c|c|c|c|c|c|c|c|c|c|c|c|c|}
\hline \multirow[b]{2}{*}{ Eks. } & \multicolumn{12}{|c|}{ Faktor dan Interaksi } & \multicolumn{3}{|c|}{ Repilikasi $\left(\mathrm{kg} / \mathrm{cm}^{2}\right)$} & \multirow[b]{2}{*}{ Jumiah } & \multirow[b]{2}{*}{ Mean } \\
\hline & \begin{tabular}{l|l}
$A$ & $B$ \\
\end{tabular} & & $\begin{array}{c}A \times B \\
(1)\end{array}$ & $\begin{array}{c}A \times B \\
(2)\end{array}$ & c) & $\begin{array}{c}A \times C \\
\text { (1) }\end{array}$ & $\begin{array}{c}A \times C \\
\text { (2) }\end{array}$ & $e$ & $D$ & & e. & & 1 & 2 & 3 & & \\
\hline 1 & \begin{tabular}{l|l}
1 & 1 \\
\end{tabular} & & \begin{tabular}{l|l}
1 \\
\end{tabular} & 1 & 1 & 1 & 1 & 1 & 1 & & 11 & & 17,5 & 17 & 17 & 51.5 & 17,167 \\
\hline 2 & $\begin{array}{lll}1 & 1 \\
\end{array}$ & & 1 & 1 & 2 & 2 & 2 & 2 & 2 & 2 & 22 & 2 & 19,5 & 19,5 & 19 & 58 & 19,333 \\
\hline 3 & 11 & & 1 & 1 & 3 & 3 & 3 & 3 & 3 & $3^{3}$ & $\begin{array}{ll}3 & 3 \\
\end{array}$ & 3 & 19 & 18,5 & 18 & 55.5 & 18,5 \\
\hline 4 & \begin{tabular}{l|l}
1 & 2 \\
\end{tabular} & & 2 & 2 & 1 & 1 & 1 & 2 & 2 & 2 & \begin{tabular}{l|l}
3 & 3 \\
\end{tabular} & 3 & 18 & 18 & 18 & 54 & 18 \\
\hline 5 & 12 & & 2 & 2 & 2 & 2 & 2 & 3 & 3 & 3 & 11 & 1 & 19 & 18,5 & 18,5 & 56 & 18,667 \\
\hline 6 & 12 & & 2 & 2 & 3 & 3 & 3 & 1 & 1 & 1 & 22 & 2 & 18 & 18 & 18,5 & 54.5 & 18,167 \\
\hline 7 & 13 & & 3 & 3 & 1 & 1 & 1 & 3 & 3 & 3 & 22 & 2 & 16,5 & 17 & 17 & 50.5 & 16,833 \\
\hline 8 & 13 & & 3 & 3 & 2 & 2 & 2 & 1 & 1 & 1 & 33 & 3 & 20 & 19 & 19,5 & 39 & 19,5 \\
\hline 9 & 13 & & 3 & 3 & 3 & 3 & 3 & 2 & 2 & 2 & 11 & 1 & 20 & 19,5 & 20 & 59.5 & 19,833 \\
\hline 10 & $\begin{array}{lll}2 & 1 \\
\end{array}$ & & 2 & 3 & 1 & 2 & 3 & 1 & 2 & 3 & 12 & 3 & 23,5 & 23 & 23 & 69.5 & 23,167 \\
\hline 11 & 21 & & 2 & 3 & 2 & 3 & 1 & 2 & 3 & 1 & 23 & 1 & 18 & 17,5 & 17,5 & 53 & 17,667 \\
\hline 12 & 21 & & 2 & 3 & 3 & 1 & 2 & 3 & 1 & 2 & \begin{tabular}{l|l}
3 & 1 \\
\end{tabular} & 2 & 20 & 21 & 20 & 61 & 20,333 \\
\hline 13 & $\begin{array}{ll}2 & 2 \\
\end{array}$ & & 3 & 1 & 1 & 2 & 3 & 2 & 3 & 1 & \begin{tabular}{l|l}
3 & 1 \\
\end{tabular} & 2 & 23 & 23,5 & 23 & 69.5 & 23,167 \\
\hline 14 & $\begin{array}{ll}2 & 2 \\
\end{array}$ & & 3 & 1 & 2 & 3 & 1 & 3 & 1 & 2 & \begin{tabular}{l|l}
12 \\
\end{tabular} & 3 & 20 & 20 & 19 & 59 & 19,667 \\
\hline 15 & 22 & & 3 & 1 & 3 & 1 & 2 & 1 & 2. & $3^{3}$ & 23 & 1 & 24 & 24,5 & 25 & 73.5 & 24,5 \\
\hline 16 & $\begin{array}{ll}23 \\
\end{array}$ & & 1 & 2 & 1 & 2 & 3 & 3 & 1 & ${ }^{2}$ & $\begin{array}{ll}2 & 3 \\
\end{array}$ & 1 & 19 & 19 & 20 & 58 & 19,333 \\
\hline 17 & 23 & & 1 & 2 & 2 & 3 & 1 & 1 & 2. & 3 & $\begin{array}{lll}3 & 1\end{array}$ & 2 & 22 & 21,5 & 22 & 65.5 & 21,833 \\
\hline 18 & $\begin{array}{ll}23 \\
\end{array}$ & & 1 & 2 & 3 & 1 & 2 & 2 & 3 & 1 & 12 & 3 & 19 & 18 & 18,5 & 55.5 & 18,5 \\
\hline 19 & \begin{tabular}{l|l}
3 & 1 \\
\end{tabular} & & 3 & 2 & 1 & 3 & 2 & 1 & 3 & 2 & 13 & 2 & 19,5 & 19,5 & 20 & 59 & 19,667 \\
\hline 20 & $\begin{array}{lll}3 & 1 \\
\end{array}$ & & 3 & 2 & 2 & 1 & 3 & 2 & 1 & 3 & $\begin{array}{ll}2 & 1\end{array}$ & 3 & 25 & 24 & 25 & 74 & 24,667 \\
\hline 21 & $\begin{array}{lll}3 & 1 \\
\end{array}$ & & 3 & 2 & ${ }^{2}$ & 2 & 1 & 3 & 2 & 1 & $\begin{array}{ll}32 \\
3\end{array}$ & 1 & 24 & 24 & 24,5 & 72.5 & 24,167 \\
\hline 22 & $\begin{array}{ll}32 \\
\end{array}$ & 2 & 1 & 3 & 1 & 3 & 2 & 2 & 1 & 3 & $\begin{array}{lll}2 & 1\end{array}$ & 2 & 18,5 & 19 & 19 & 38 & 18,833 \\
\hline 23 & $\begin{array}{ll}3 & 2 \\
\end{array}$ & & 1 & 3 & 2 & 1 & 3 & 3 & 2 & 1 & $\begin{array}{ll}13 \\
\end{array}$ & 2 & 18,5 & 18 & 18,5 & 55 & 18,333 \\
\hline 24 & $\begin{array}{ll}3 & 2 \\
\end{array}$ & & 1 & 3 & 3 & 2 & 1 & 1 & 3. & ${ }^{2}$ & $\begin{array}{lll}2 & 1\end{array}$ & 3 & 17,5 & 18 & 17 & 52.5 & 17,5 \\
\hline 25 & $\begin{array}{ll}3 & 3 \\
\end{array}$ & & 2 & 1 & 1 & 3 & 2 & 3 & 2 & 1 & $\begin{array}{l}2 \\
2\end{array}$ & 3 & 23,5 & 24 & 24 & 71.5 & 23,833 \\
\hline 26 & $\begin{array}{ll}3 & 3 \\
\end{array}$ & & 2 & 1 & 2 & 1 & 3 & 1 & 3. & & $\begin{array}{l}3 \\
3^{2}\end{array}$ & & 22 & 21,5 & 22 & 65.5 & 21,833 \\
\hline 27 & $\begin{array}{ll}3 & 3 \\
\end{array}$ & & 2 & 1 & 3 & 2 & 1 & & & & & & 22 & 22,5 & 23 & 67.5 & 22,5 \\
\hline
\end{tabular}

Tabel 3. Matriks Ortogonal $L_{27}\left(3^{13}\right)$

\section{HASIL DAN PEMBAHASAN}

Untuk mengetahui faktor-faktor apa saja yang signifikan yang berpengaruh terhadap kuat tekan genteng beton, diperlukan analisa dan pengolahan data eksperimen dengan menggunakan perhitungan nilai mean dan ditranformasikan dalam tabel analisis variansi.

\section{Pengaruh Level Faktor Terhadap Rata-Rata Kuat Tekan Genteng Beton}

Untuk mengidentifikasi pengaruh level dari faktor terhadap rata-rata kuat tekan genteng beton, dilakukan pengolahan data respon (data asli) kuat tekan genteng beton yang diperoleh langsung dari pengujian kuat tekan genteng beton. Hasil perhitungan nilai rata-rata kuat tekan genteng beton melalui kombinasi level dari masingmasing faktor dapat dilihat pada Tabel 4. 
Tabel 4. Respon Rata-rata Kuat Tekan Genteng Beton dari Pengaruh Faktor

\begin{tabular}{|l|l|l|l|l|l|l|l|l|}
\hline & A & B & $\begin{array}{l}\mathrm{A} \times \mathrm{B} \\
(1)\end{array}$ & $\begin{array}{l}\mathrm{A} \times \mathrm{B} \\
(2)\end{array}$ & $\mathrm{C}$ & $\begin{array}{l}\mathrm{A} \times \mathrm{C} \\
(1)\end{array}$ & $\begin{array}{l}\mathrm{A} \mathrm{C} \\
(2)\end{array}$ & $\mathrm{D}$ \\
\hline Level 1 & 18,444 & 20,519 & 18,815 & 21,167 & 20,000 & 20,019 & 19,482 & 20,019 \\
\hline Level 2 & 20,907 & 19,648 & 20,463 & 20,333 & 20,167 & 20,815 & 20,352 & 21,444 \\
\hline Level 3 & 21,259 & 20,444 & 21,333 & 19,111 & 20,444 & 19,778 & 20,778 & 19,148 \\
\hline Selisih & 2,815 & 0,871 & 2,518 & 2,056 & 0,444 & 1,037 & 1,296 & 2,296 \\
\hline Ranking & 1 & $\mathbf{7}$ & $\mathbf{2}$ & $\mathbf{4}$ & $\mathbf{8}$ & 6 & $\mathbf{5}$ & 3 \\
\hline
\end{tabular}

Dari tabel respon, kombinasi level faktor optimum dicapai pada nilai rata-rata respon kuat tekan genteng beton dengan nilai yang paling besar dari tiap faktor, yaitu faktor $A_{3}$, interaksi $A \times B(1)$, faktor $D_{2}$, dan interaksi $A \times B(2)$.

Pengaruh faktor $A$ dan $B$ untuk 9 kombinasi faktor sebagai berikut:

Rata-rata pengaruh $A_{1} B_{1}=(17,167+19,333+18,500) / 3=18,333$

Rata-rata pengaruh

$A_{1} B_{2}=(18,000+18,667+18,167) / 3=18,278$

Rata-rata pengaruh

$$
A_{1} B_{3}=(16,833+19,500+19,833) / 3=18,722
$$

Rata-rata pengaruh

$A_{2} B_{1}=(23,167+17,667+20,333) / 3=20,389$

Rata-rata pengaruh

$A_{2} B_{2}=(23,167+19,667+24,500) / 3=22,445$

Rata-rata pengaruh

$A_{2} B_{3}=(19,333+21,833+18,500) / 3=19,889$

Rata-rata pengaruh

$A_{3} B_{1}=(19,667+24,667+24,167) / 3=22,834$

Rata-rata pengaruh

$A_{3} B_{2}=(18,833+18,333+17,500) / 3=18,222$

Rata-rata pengaruh

$A_{3} B_{3}=(23,833+21,833+22,500) / 3=22,722$

Untuk mencapai nilai target lebih besar, lebih baik (larger-the-better), maka penentuan level faktor yang optimal adalah yang mendapatkan hasil pengujian kuat tekan yang paling besar. Kombinasi level faktor optimum, adalah: $A_{3}=$ Semen 0,8 kg; $D_{2}=$ Debu batu 2,8 kg dan kombinasi level interaksi optimum adalah: $A_{3} \times B_{1}=$ Semen $0,8 \mathrm{~kg}$ dan air 0,3 lt.

\section{Analisa Varians Rata-rata Kuat Tekan Genteng Beton}

Dengan menggunakan model analisis dua arah yang terdiri dari perhitungan derajat bebas, jumlah kuadrat, rata-rata jumlah kuadrat, dan F-rasio Untuk mengetahui faktor/interaksi yang signifikan terhadap rata-rata kuat tekan genteng beton, maka dilakukan penggabungan (pooling up) beberapa faktor ke dalam error. Faktorfaktor yang tidak signifikan dikumpulkan sebagai error.

\section{Pooling Up Faktor}

Penggabungan faktor sebagai error dimulai dari faktor dengan jumlah kuadrat/Sum of Square (SS) terkecil dari faktor yang tidak signifikan dengan jumlah kuadrat error. Jumlah kuadrat terkecil dari faktor yang tidak signifikan yaitu faktor $C$, faktor $B$, dan interaksi faktor $A \times C(1)$. Penggabungan tersebut menyebabkan struktur tabel analisis varians berubah.

Tabel 5 merupakan tabel analisis variansi rata-rata kuat tekan genteng beton dengan pooling pertama, faktor $C$ digabungkan ke dalam variansi error.

Tabel 5 Analisis Variansi Penggabungan I

\begin{tabular}{|c|c|c|c|c|c|c|}
\hline Sumber & $V$ & $S S$ & $M S$ & $F_{\text {hitumg }}$ & $F_{\text {tabel }}$ & Kesimpulan \\
\hline$A$ & 2 & 42,340 & 21,170 & 3,081 & $F_{(0,10 ; 2 ; 4)}=4,32$ & $H_{0}$ diterima \\
\hline$B$ & 2 & 4,191 & 2,096 & 1,206 & $F_{(0,10 ; 2 ; 4)}=4,32$ & $H_{0}$ diterima \\
\hline$A \times B(1)$ & 4 & 29,475 & 7,364 & 1,724 & $F_{(0,10 ; 444)}=4,11$ & $H_{0_{\text {diterima }}}$ \\
\hline$A \times B(2)$ & 4 & 19,244 & 4,811 & 1,473 & $F_{(0,10 ; 44)}=4,11$ & $H_{0_{\text {diterima }}}$ \\
\hline$C$ & \multicolumn{7}{|c|}{ Pooling } \\
\hline$A \times C(1)$ & 4 & 5,304 & 1,326 & 1,130 & $F_{(0,10 ; 44)}=4,11$ & $H_{0_{\text {diterima }}}$ \\
\hline$A \times C(2)$ & 4 & 7,857 & 1,964 & 1,193 & $F_{(0,10 ; 44)}=4,11$ & $H_{0_{\text {diterima }}}$ \\
\hline$D$ & 2 & 24,188 & 12,094 & 2,189 & $F_{(0,10 ; 24)}=4,32$ & $H_{0}$ diterima \\
\hline Error & 4 & 40,689 & 10,172 & - & - & - \\
\hline Total & 26 & 173,288 & - & - & - & - \\
\hline
\end{tabular}

Keterangan :

$H_{0}$ : Tidak ada pengaruh faktor atau interaksinya terhadap kuat tekan genteng beton

$H_{1}$ : Ada pengaruh faktor atau interaksinya terhadap kuat tekan genteng beton.

Tabel 6, merupakan tabel analisis variansi rata-rata kuat tekan genteng beton dengan pooling kedua, faktor $B$ digabungkan ke dalam variansi error

Tabel 6. Analisis Varians Penggabungan II

\begin{tabular}{|c|c|c|c|c|l|l|}
\hline Sumber & $V$ & $S S$ & $M S$ & $F_{\text {hitumg }}$ & $F_{\text {tabel }}$ & Kesimpulan \\
\hline$A$ & 2 & 42,340 & 21,170 & 3,830 & $F_{(0,10 ; 26)}=3,46$ & $H_{0}$ diterima \\
\hline$B$ & \multicolumn{7}{|c|}{ Pooling } \\
\hline$A \times B(1)$ & 4 & 29,475 & 7,364 & 1,984 & $F_{(0,10 ; 46)}=3,18$ & $H_{0}$ diterima \\
\hline$A \times B(2)$ & 4 & 19,244 & 4,811 & 1,643 & $F_{(0,10 ; 6)}=3,18$ & $H_{0}$ diterima \\
\hline$A \times C(1)$ & 4 & 5,304 & 1,326 & 1,177 & $F_{(0,10 ; 46)}=3,18$ & $H_{0}$ diterima \\
\hline$A \times C(2)$ & 4 & 7,857 & 1,964 & 1,263 & $F_{(0,10 ; 46)}=3,18$ & $H_{0}$ diterima \\
\hline$D$ & 2 & 24,188 & 12,094 & 2,617 & $F_{(0,0 ; 46)}=3,18$ & $H_{0}$ diterima \\
\hline$E$ Error & 4 & 40,689 & 10,172 & - & - & - \\
\hline Total & 26 & 173,288 & - & - & - & - \\
\hline
\end{tabular}

Tabel 7, merupakan tabel analisis varians rata-rata kuat tekan genteng beton dengan pooling ketiga, faktor interaksi $A \times C(1)$ digabungkan ke dalam variansi error. 
Tabel 7. Analisis Variansi Penggabungan III

\begin{tabular}{|c|c|c|c|c|c|c|}
\hline Sumber & V & ss & .MS & $F_{\text {hitumg }}$ & $F_{\text {tabel }}$ & Kesimpulan \\
\hline$A$ & 2 & 42,340 & 21,170 & 5,219 & $F_{(0,10 ; 2: 10)}=2,92$ & $H_{0 \text { ditolak }}$ \\
\hline$A \times B(1)$ & 4 & 29,475 & 7,364 & 2,468 & $F_{(0,10 ; 410)}=2,61$ & $H_{0}$ diterima \\
\hline$A \times B(2)$ & 4 & 19,244 & 4,811 & 1,959 & $F_{(0,10 ; 410)}=2,61$ & $H_{0}$ diterima \\
\hline$A \times C(1)$ & \multicolumn{6}{|c|}{ Pooling } \\
\hline$A \times C(2)$ & 4 & 7,857 & 1,964 & 1,391 & $F_{(0,10 ; 410)}=2,61$ & $H_{0}$ diterima \\
\hline D & 2 & 24,188 & 12,094 & 3,410 & $F_{(0,10 ; 210)}=2,92$ & $H_{0}$ ditolak \\
\hline Error & 10 & 50,184 & 5,018 & - & . & $\cdot$ \\
\hline Total & 26 & 173,288 & . & . & . & . \\
\hline
\end{tabular}

Pada eksperimen ini dilakukan tiga kali Pooling Up Faktor. Untuk mengetahui seberapa besar kontribusi yang diberikan oleh masing-masing faktor dan interaksi, terlebih dahulu dihitung $S S^{\prime}$ seperti di bawah in

\section{KESIMPULAN}

Berdasarkan pembahasan maka kesimpulan dalam penelitian ini adalah:

1. Faktor-faktor yang sangat berpengaruh terhadap kuat tekan genteng beton adalah semen yang memberikan kontribusi sebesar 18,642\% dan debu batu 8,167\%.

2. Berdasarkan contoh kasus yang diambil, maka kombinasi yang tepat untuk memperoleh kuat tekan genteng beton yang yang diinginkan adalah $A_{3} A_{3} B_{1} D_{2}$

\section{DAFTAR PUSTAKA}

Soejanto, Irwan. Desain Eksperimen dengan Metode Taguchi. Surabaya: Graha Ilmu; 2009.

Bagchi, Tapan P. Taguchi Methods Explained Practical Steps to Robust Design. Kanpur: Prentice; 1993.

$$
\begin{aligned}
& S S_{A}^{\prime}=S S_{A}-M S_{e}\left(V_{A}\right)=42,340-5,018(2)=32,304 \\
& S S_{A B(1)}^{\prime}=S S_{A B(1)}-M S_{e}\left(V_{A B(1)}\right)=29,457-5,018(4)=9,403 \\
& S S_{A B(2)}^{\prime}=S S_{A B(2)}-M S_{e}\left(V_{A B(2)}\right)=19,244-5,018(4)=-0,828 \\
& S S_{A C(2)}^{\prime}=S S_{A C(2)}-M S_{e}\left(V_{A C(2)}\right)=7,857-5,018(4)=-12,215 \\
& S S_{D}^{\prime}=S S_{D}-M S_{e}\left(V_{D}\right)=24,188-5,018(2)=14,152
\end{aligned}
$$

Sedangkan persen kontribusi masing-masing faktor dan interaksi dihitung dengan rumus:

$$
\begin{aligned}
& \rho=\frac{S S_{\text {faktor }}^{\prime}}{S S_{T}} \times 100 \% \\
& \rho_{A}=\frac{32,304}{173,288} \times 100 \%=18,642 \% \\
& \rho_{A B(1)}=\frac{9,403}{173,288} \times 100 \%=5,426 \% \\
& \rho_{A B(2)}=\frac{-0,828}{173,288} \times 100 \%=-0,478 \% \\
& \rho_{A C(2)}=\frac{-12,215}{173,288} \times 100 \%=-7,049 \% \\
& \rho_{D}=\frac{14,152}{173,288} \times 100 \%=8,167 \%
\end{aligned}
$$

Dari perhitungan di atas, terlihat bahwa faktor $A$ (semen) yang memberikan kontribusi terbesar terhadap rata-rata kuat tekan genteng beton, yaitu sebesar 18,642\% kemudian faktor $D$ (debu batu) yakni 8,167\%. 